\title{
Podkładki ceramiczne do spawania stali specjalnych nierdzewnych w osłonie gazu obojętnego
}

\section{Ceramic backings for welding special stainless steel in the inert gas}

\section{Streszczenie}

Przedstawiono wyniki badań nad podkładkami ceramicznymi umożliwiającymi doprowadzenie gazu obojętnego do powierzchni elementów spawanych. Dzięki segmentowej, wahliwej konstrukcji podkładek jest możliwe spawanie elementów płaskich i łukowych. Badania prowadzono na podkładkach wykonanych $\mathrm{z}$ dwóch rodzajów tworzyw kordierytowo-mullitowych. Omówiono wyniki badań technologicznych spawania blach austenitycznych kwasoodpornych i żaroodpornych na specjalnym stanowisku oraz spawania w warunkach przemysłowych blach kwasoodpornych o grubości 1,2 i $5 \mathrm{~mm}$. We wszystkich przypadkach uzyskano właściwie uformowaną grań spoiny na poziomie jakości $B$.

Słowa kluczowe: podkładka ceramiczna, stal nierdzewna, gaz obojętny

\section{Wstęp}

W przypadku łączenia stali wysokostopowych, zwłaszcza typu dupleks i superdupleks, stopów niklu, stali nierdzewnych, stali energetycznych, stopów miedzi i stopów tytanu konieczne jest zastosowanie podczas spawania osłony grani spoiny za pomocą gazu obojętnego.

W wielu przypadkach stosowane są indywidualnie projektowane podkładki miedziane umożliwiające doprowadzenie gazu. Ich wadą, poza ceną, jest dostosowanie kształtu do konkretnych złączy. Zmiana kształtu jest praktycznie niemożliwa. Również istotna jest wrażliwość na niedokładności łączenia elementów przed spawaniem, czego powodem jest ich

\section{Abstract}

The results of investigations on ceramic backings system making possible supply of invert gas to the welded surfaces and due to their swinging construction application for both the flat and arch surfaces has been presented. The two types of cordierite-mullite materials were used for backings. The tests of welding of austenitic acid resistant and heat resistant steel sheets with thickness of 1.2 and $5 \mathrm{~mm}$ carried on special device and in industrial conditions were described. The properly formed butt joins of class $\mathrm{B}$ were obtained in all cases.

Key words: ceramic backing, stainless steel, inert gas

sztywna budowa, a także duża przewodność cieplna powodująca zbyt szybkie stygnięcie.

Celem podjętych badań było opracowanie podkładek ceramicznych umożliwiających wprowadzenie gazu obojętnego do powierzchni spawanych, spełniających następujące wymagania:

1. Uzyskanie wymaganej jakości spoiny podczas spawania stali wysokostopowych, a w szczególności stali nierdzewnych.

2. Spawanie jednostronne.

3. Ograniczenie zużycia gazu.

4. Dobre przyleganie do spawanych powierzchni prostych i łukowych.

5. Łatwość łączenia i mocowania do blach.

6. Możliwość wielokrotnego użycia.

Dr inż. Jerzy Czechowski, dr inż. Alicja Pawełek - Instytut Ceramiki i Materiałów Budowlanych, Gliwice, mgr inż. Krystyna Warsz - Instytut Spawalnictwa, Gliwice.

Autor korespondencyjny/Corresponding author: p.glowienkowski@icimb.pl 


\section{Projektowanie podkładek}

W wyniku badań $[1,2]$ zaprojektowano kształt podkładek uniwersalnych segmentowych umożliwiających spawanie powierzchni płaskich i po łuku z doprowadzeniem gazu do miejsca spawania (rys. 1). Podkładki te dobrze przylegają do powierzchni i są szczelnie mocowane pod granią spawanych blach za pomocą odpowiedniej taśmy samoprzylepnej.
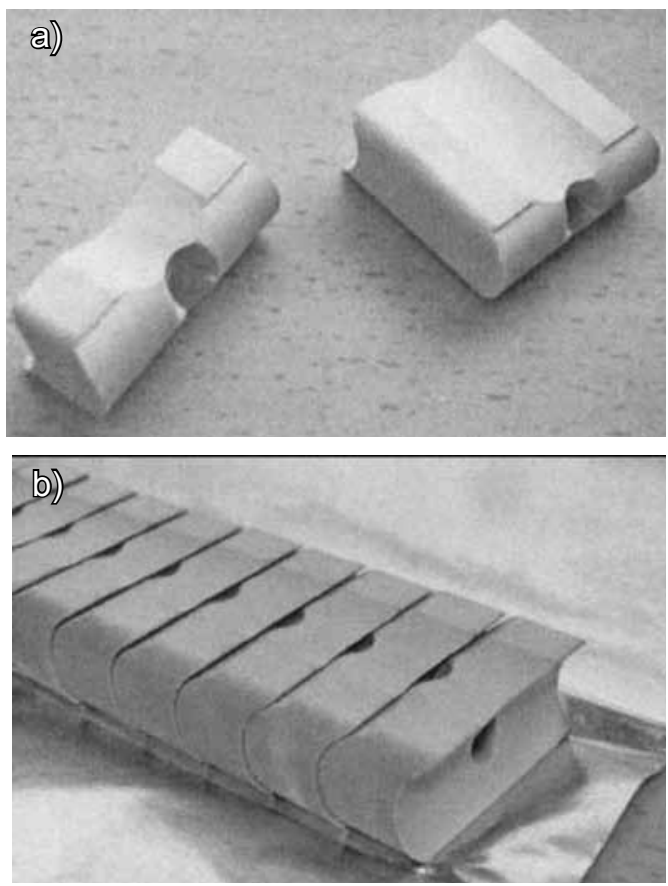

Rys. 1. Podkładki segmentowe: a) W7 i W20; b) W7 na taśmie samoprzylepnej

Fig. 1. Sectional swinging backings: a) W7 and W20; b) W7 on self adhesive tape

Liczba połączonych ze sobą wahliwie podkładek na taśmie może być dowolna. Ze względów praktycznych założono, że w warunkach produkcyjnych standardowa długość segmentów umieszczonych na taśmie będzie wynosić $600 \mathrm{~mm}$.

Zaprojektowano segmenty o grubości $11 \mathrm{~mm}$ i długości $20 \mathrm{~mm}$ (W20) do spawania elementów o mniejszej średnicy i $7 \mathrm{~mm}$ (W7) o dużej. W badaniach skoncentrowano się na dwóch rodzajach tworzyw ceramicznych mulitowo-kordierytowych A i B otrzymywanych z granulatów prasowanych jednorazowo. Ich skład chemiczny podano $w$ tablicy I.

Tablica I. Podstawowy skład chemiczny badanych tworzyw (główne składniki)

Table I. Basic chemical compounds of investigated materials (main)

\begin{tabular}{|c|c|c|}
\hline \multirow{2}{*}{ Składnik } & \multicolumn{2}{|c|}{ Zawartość, \% wag. } \\
\cline { 2 - 3 } & Tworzywo A & Tworzywo B \\
\hline $\mathrm{SiO}_{2}$ & 55 & 47 \\
\hline $\mathrm{Al}_{2} \mathrm{O}_{3}$ & 32 & 32 \\
\hline $\mathrm{MgO}$ & 8 & 5,5 \\
\hline
\end{tabular}

Badano wpływ nacisku formowania i temperatury wypalania na właściwości tworzyw. W tablicy II zestawiono właściwości tworzyw uzyskanych w zoptymalizowanych warunkach formowania i wypalania.

Tablica II. Właściwości wypalonych tworzyw mulitowo-kordierytowych Table II. Properties of fired mullit-cordierite

\begin{tabular}{|c|c|c|}
\hline Właściwość & Tworzywo A & Tworzywo B \\
\hline Gęstość pozorna, g/cm & 1,91 & 2,60 \\
\hline Porowatość otwarta, \% & 28,0 & 6,6 \\
\hline Nasiąkliwość, \% & 14,6 & 2,5 \\
\hline Przewodność cieplna & & \\
W/mK: & & \\
w $25^{\circ} \mathrm{C}$ & $1,31 \pm 0,02$ & $1,0 \pm 0,01$ \\
w $1250^{\circ} \mathrm{C}$ & $2,80 \pm 0,18$ & $1,47 \pm 0,26$ \\
\hline
\end{tabular}

Oznaczenia gęstości pozornej, porowatości otwartej i nasiąkliwości wykonano metodami znormalizowanymi, natomiast oznaczenie przewodności cieplnej przeprowadzono metodą laser-flesh przy użyciu urządzenia LFA427.

\section{Próby technologiczne spawania z użyciem podkładek}

Próby technologiczne spawania w atmosferze ochronnej złączy doczołowych z użyciem opracowanych podkładek ceramicznych przeprowadzono w Instytucie Spawalnictwa. Zaadaptowane do tego celu stanowisko przedstawiono na rysunku 2. W jego skład wchodziły: traktor spawalniczy A2/A6 firmy ESAB (1), urządzenie do spawania metodą TIG typu V40 firmy Lorch (2), uchwyt spawalniczy TIG z możliwością podawania zimnego drutu ABITIG-WH400 firmy Binzel (3) oraz oprzyrządowanie ustalająco-mocujące z zaciskami firmy Destaco (4).

Spawano blachy ze stali austenitycznej kwasoodpornej X5CrNi18-10, stali dupleks X2CrNiMoN22-5-3 i stali austenitycznej żaroodpornej X6CrNiMoTi17-12-2 o grubości 1 i $2 \mathrm{~mm}$.

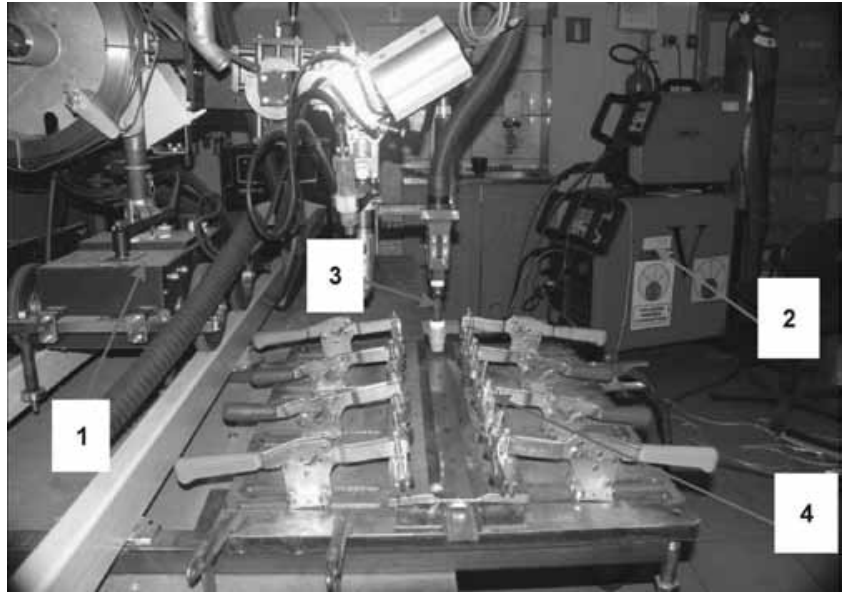

Rys. 2. Stanowisko do badań technologicznych spawania z zastosowaniem podkładek

Fig. 2. The device for technological tests of welding using backings 
Spoiwem był drut LNM 304Lsi (PN-EN ISO 14343A-G-199 LSi). Jako gazu osłonowego użyto czystego argon (zgodny z PN-EN ISO 14175-II-Ar).

W tablicy III podano warunki procesów spawania.

Tablica III. Warunki spawania

Table III. Welding conditions

\begin{tabular}{|c|c|c|}
\hline \multirow{2}{*}{ Parametr } & \multicolumn{2}{|c|}{ Grubość blachy } \\
\cline { 2 - 3 } & $1 \mathrm{~mm}$ & $2 \mathrm{~mm}$ \\
\hline Natężenie prądu, A & 55 & 120 \\
\hline Napięcie łuku, V & $9,4 \div 9,6$ & $11,4 \div 11,6$ \\
\hline $\begin{array}{c}\text { Natężenie przepływu gazu } \\
\text { osłonowego w uchwycie spa- } \\
\text { walniczym, l/min }\end{array}$ & 10 & 10 \\
\hline $\begin{array}{c}\text { Prędkość spawania, m/min } \\
\begin{array}{c}\text { Odległość elektrody wolframo- } \\
\text { wej od powierzchni spawanego } \\
\text { elementu, mm }\end{array}\end{array}$ & $3,5 \div 4,5$ & $3,5 \div 4,5$ \\
\hline
\end{tabular}

Próby wstępne spawania blachy austenitycznej X5CrNi18-10 wykazały, że największy wpływ na jakość grani spoiny ma natężenie przepływu gazu osłonowego od jej strony (mierzonego na wylocie z podkładki). Ustalono, że najlepsze wyniki osiąga się, gdy natężenie to wynosi $1 \mathrm{l} / \mathrm{min}$. Zastosowanie mniejszego natężenia przepływu powodowało nadmierne utlenianie powierzchni grani spoiny i obszarów do niej przyległych (rys. 3), a większe natężenie powodowało wklęśnięcia grani.

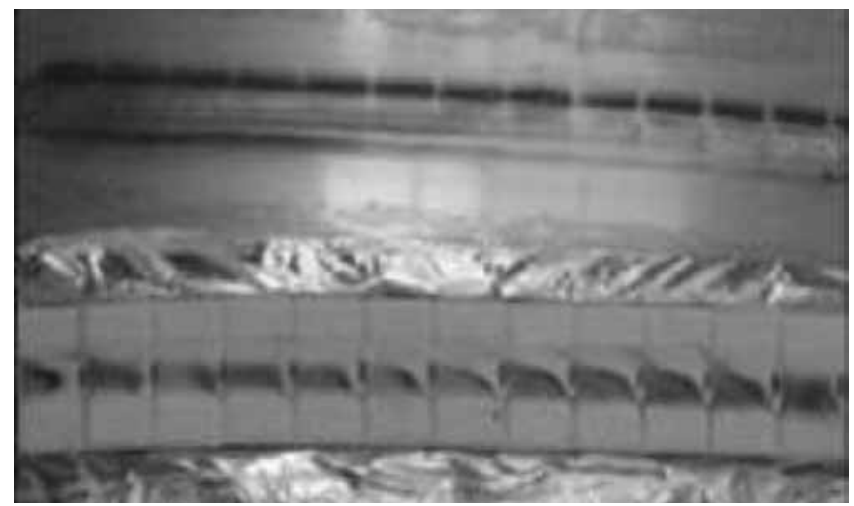

Rys. 3. Złacza doczołowe powierzchniowo utlenione przy zastosowaniu podkładek ceramicznych z płytkim rowkiem - niedostateczny przepływ argonu

Fig. 3. Butt joints surface using ceramic backings with a shallow keyway - insufficient of argon

Po zbadaniu efektów prób spawania zdecydowano o konieczności pogłębienia rowka w podkładkach w celu zapewnienia odpowiedniej przestrzeni pomiędzy podkładką a blachą w celu uzyskania przepływu gazu o właściwym natężeniu.

Przeprowadzone próby spawania wytypowanych blach przy uwzględnieniu wyżej opisanych warunków przepływu argonu wykazały, że zastosowanie uniwersalnych podkładek ceramicznych umożliwia spawanie w osłonie gazowej.
Uzyskano w większości przypadków czystą grań spoiny, bez zanieczyszczeń tlenkowych (rys. 4 i 5). Szczególnie korzystne rezultaty uzyskano przy zastosowaniu podkładek z tworzywa mulitowo-kordierytowego B charakteryzującego się większą zwartością $\mathrm{w}$ porównaniu z tworzywem A.

Badania metalograficzne makroskopowe połączeń wykazały, że złącza są wykonane prawidłowo, nie występują w nich niezgodności spawalnicze i charakteryzuje je poziom jakości B wg PN-EN ISO 5817 (rys. 6 i 7) [3].

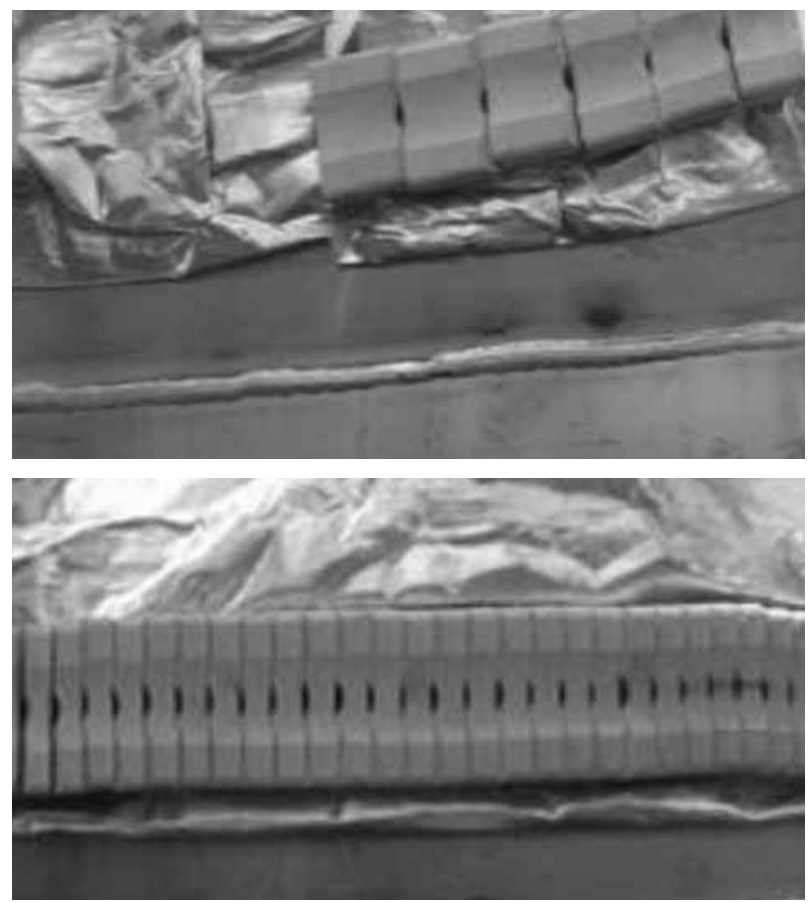

Rys. 4. Grań spoiny złącza doczołowego blach o grubości $2 \mathrm{~mm}$ spawanych przy użyciu podkładek $z$ tworzywa kordierytowo-mulitowego $B$ Fig. 4. Butt joints surface of metal sheets with thickness of $2 \mathrm{~mm}$ using cordierite-mullite backings type $B$

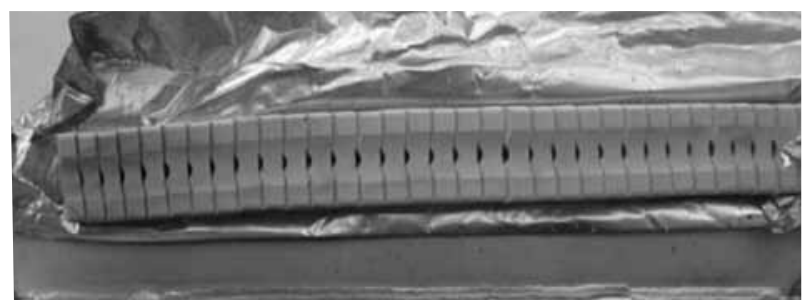

Rys. 5. Grań spoiny złacza doczołowego blach o grubości $2 \mathrm{~mm}$ ze stali X2CrNiMoN22-5-3 z zastosowaniem podkładki uniwersalnej W7 z tworzywa A

Fig. 5. Butt joints surface of $2 \mathrm{~mm}$ trick $X 2 \mathrm{CrNiMoN} 22-5-3$ grade steel using universal W7 backings of type $A$

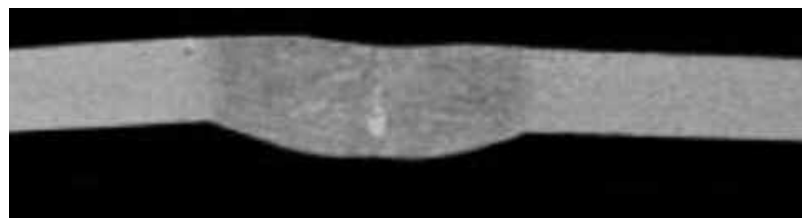

Rys. 6. Makrostruktura złącza spawanego blach o grubości $1 \mathrm{~mm}$ ze stali X5CrNi18-10 uzyskanego przy użyciu podkładek z tworzywa B Fig. 6. Macrostructure of butt joint of $1 \mathrm{~mm}$ trick $X 5 \mathrm{CrNi18}-10$ steel using backings of type $B$ 


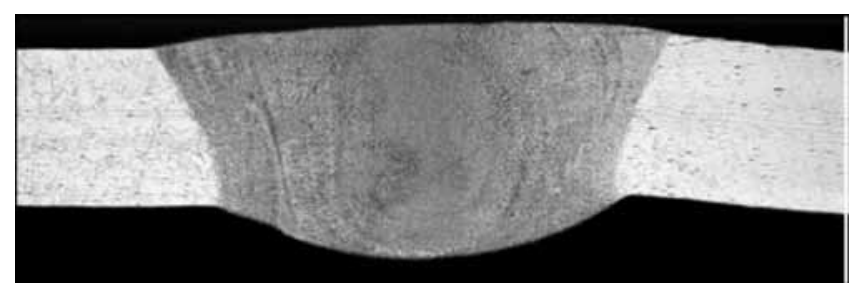

Rys. 7. Makrostruktura złącza spawanego blach o grubości $2 \mathrm{~mm}$ ze stali X5CrNi18-10 uzyskanego przy użyciu podkładek z tworzywa A Fig. 7. Macrostructure of butt joint of $2 \mathrm{~mm}$ trick X5CrNi18-10 steel using backings of grade $\mathrm{A}$

\section{Testy przemysłowe spawania}

W Zakładzie „Cabinplant” S.A. w Kątach Wrocławskich przeprowadzono testy spawania powszechnie stosowanych w przemyśle spożywczym blach ze stali $\mathrm{X} 5 \mathrm{Cr}$ Ni18-10 o grubości $1,5 \mathrm{~mm}$.

Spawano ręcznie płyty i rury o średnicy $250 \mathrm{~mm}$ metodą TIG urządzeniem firmy Kemppi Master Tig 2000 MLS. Argon doprowadzono do podkładki ceramicznej. Podkładki były szczelnie przyklejone do blach za pomocą taśmy samoprzylepnej.

Zwracano szczególną uwagę na szczelność w miejscu dopływu gazu. Uzyskano właściwie uformowaną grań spoiny bez obecności tlenków na jej powierzchni, szczególnie przy zastosowaniu tworzywa B (rys. 8). Na widoczną miejscami zmianę koloru obszarów położonych w pobliżu krawędzi spoiny mogło mieć wpływ niedostateczne odtłuszczenie powierzchni blach przed spawaniem.
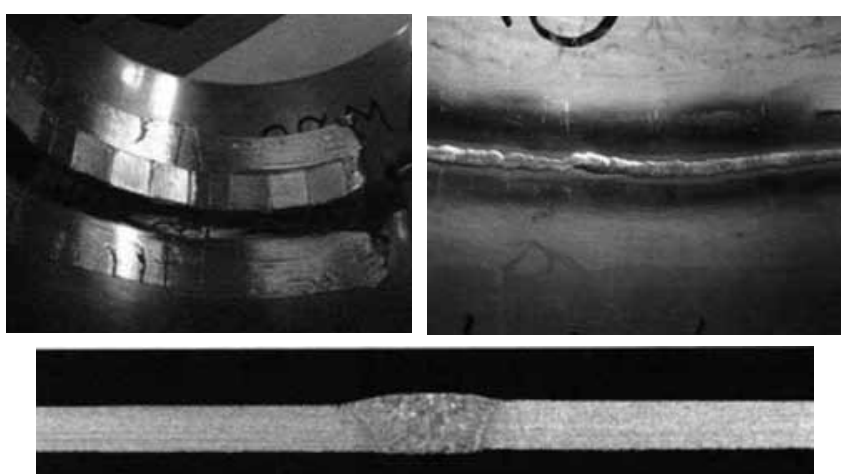

Rys. 8. Widok zamocowania podkładek W20 z tworzywa B na powierzchniach łukowych, grani uzyskanej spoiny oraz jej makrostruktury

Fig. 8. Mounting backings W20 type B on the surface of the arcing, welding surface and the macrostructure

Makroskopowe badania metalograficzne nie wykazały niezgodności. Wykonane złącze zakwalifikowano jako poziom jakości $B$.

Przeprowadzone w Przedsiębiorstwie „Teja” próby spawania blach nierdzewnych o grubości $5 \mathrm{~mm} \mathrm{z} \mathrm{za-}$ stosowaniem uniwersalnych podkładek kordierytowo-mulitowych potwierdziły skuteczność osłony gazowej i dobrą jakość uzyskanej spoiny [4].

\section{Wnioski}

- Przeprowadzone próby technologiczne spawania metodą TIG ręcznie i w sposób zmechanizowany blach ze stali austenitycznych i austenityczno-ferrytycznych o grubości do $5 \mathrm{~mm}$ z użyciem opracowanych podkładek ceramicznych wykazały możliwość zapewnienia wysokiej jakości spoiny przy znacznej oszczędności zużycia gazu osłonowego.

- Budowa segmentowa podkładek umożliwia spawanie zarówno elementów płaskich, jak i o bardziej złożonej geometrii, a pogłębienie rowka do ok. $3 \mathrm{~mm}$ zapewnia odpowiednią przestrzeń dla gazu osłonowego i wyeliminowanie powstawania nalotu tlenkowego.

- Zastosowana taśma samoprzylepna zapewnia szczelność mocowania podkładek do łączonych powierzchni blach.

\section{Literatura}

[1] Pawełek A., Czechowski J., Skóra J., Sołtys P.: Podkładki ceramiczne do formowania grani spoiny w osłonie gazowej. Sprawozdanie $\mathrm{nr}$ 3475/100280/BT/2005 - niepublikowane.

[2] Pawełek A., Czechowski J., Śliwa A., Stec K.: Opracowanie i wdrożenie technologii produkcji ceramicznych podkładek do spawania w osłonie gazu obojętnego. Sprawozdanie nr 3638/100361/BT/2009 - niepublikowane.
[3] Pfeiffer T., Warsz K.: Badania wpływu procesu spawania łukowego przy zastosowaniu doświadczalnych wariantów podkładek ceramicznych, formujących grań spoiny w osłonie gazu, na jakość złączy spawanych ze stali wysokostopowych. Sprawozdanie Instytutu Spawalnictwa nr Gn-17(B-191/10) - nie publikowane.

[4] Pawełek A., Czechowski J., i zespół: Innowacyjne ceramiczne podkładki segmentowe do spawania w osłonie gazowej stali i stopów specjalnych i technika ich stosowania. Raport Roczny z projektu w ramach przedsięwzięcia „IniTech”- 2010. 